\title{
Compositional Quality of Milk and Its Contaminants on Physical and Chemical Concern: A Review
}

\author{
Dilip Kumar ${ }^{1 *}$, Dipti Rai ${ }^{2}$, Paras Porwal ${ }^{3}$ and Sudhir Kumar ${ }^{4}$
}

${ }^{1}$ Department of Animal Husbandry and Dairying, Institute of Agricultural Sciences, Banaras Hindu University, Varanasi, U.P., India

${ }^{2}$ Department of Food Technology, Chhatrapti Sahu Ji Maharaj University, Kanpur, U.P., India

${ }^{3}$ Amity Institute of Biotechnology, Amity University Uttar Pradesh, Lucknow Campus, India

${ }^{4}$ Centre of Food Science and Technology, Institute of Agricultural Sciences, Banaras Hindu University, Varanasi, U.P., India

*Corresponding author

\section{A B S T R A C T}

\begin{tabular}{|c|}
\hline Keywords \\
\hline $\begin{array}{l}\text { Quality milk, Aflatoxins, } \\
\text { Heavy metals residue, } \\
\text { Pesticides and } \\
\text { insecticides residue, } \\
\text { Hormone residue }\end{array}$ \\
\hline Article Info \\
\hline $\begin{array}{l}\text { Accepted: } \\
10 \text { April } 2018 \\
\text { Available Online: } \\
10 \text { May } 2018\end{array}$ \\
\hline
\end{tabular}

India is a highest milk producer. Whereas the concept of qualitative milk for consumer is the most valuable things related to milk production and its processing. The quality of raw milk is the primary factor determining the quality of milk products. Good quality raw milk has to be free of debris and sediment; free of off-flavours and abnormal colour and odour; low in bacterial count; free of chemicals (e.g., antibiotics, detergents); and of normal composition and acidity. Physical contaminants like dirt particles, hair, leaves, rubber and mettle particles, paper pieces etc. can get entry in to the milk at the time of milking. Chemical contamination in milk comprise may introduce during milk production, dairy processing and packaging. Aflatoxins, pesticides and insecticides residue, antimicrobial residue, antibiotic residue and heavy metals residue are chemical contaminants that can enter to animal feed and they have some residue in milk. Hormonal residue such as steroid hormones and bovine growth hormones is an other type of contamination which exerting profound biological effects in animals and humans.

\section{Introduction}

Milk is complex biological fluid secreted by mammals for the nourishment and to provide immunological protection for their young. Milk is considered as a complete food because it contains proteins, fat, carbohydrates, minerals, vitamins and water (Robinson, 1990). Milk is considered as nature's single most complete food (O'Mahony, 1988) and is definitely one of the most valuable and regularly consumed foods. But at the same time, it is highly vulnerable to bacterial contamination and hence is easily perishable (Kim et al., 1983; OECD, 2005). Though it is provided with high nutritional value, but is an excellent medium for microbial growth (Uddin, 1999). Chemically, milk is a complex mixture of fat, protein, carbohydrates, minerals, vitamins and other miscellaneous 
constituents dispersed in water, make it a complete diet (Haug et al., 2007). Except high nutritional value, presence of pathogenic bacteria in milk can results with high health danger and eventually may cause death of consumers. In India, milk is produced mostly in non-standardized way and is usually supplied to the consumers from the urban and rural areas by milkmen. Although there is little milk pockets specially milk vita, and some established dairy farms where surplus milk is readily available in Bangladesh, this perishable product has never received particular attention in hygienic distribution to the consumers (Khan et al., 2008).

The concept of pasteurized and UHT milk in India is not very old idea and proved to be very popular among consumers. The microbial status of these heat treated milk gets attention nowadays. Although heat treated milk like pasteurized and UHT milk shouldn't contain pathogenic bacteria but if milk dose not processed properly, it may results with high microbial load in milk. Pasteurized milk is recommended to be consumed within seven days from the production and for UHT milk it is six months from the production date.

But poor initial milk quality, faulty processing, problem in preservation at the consumer side may results into microbial contamination in milk and thus there are great chances of deterioration of milk much prior than the recommended preservation time. The Food safety Standard Authority of India (FSSAI) obliges various chemical and sanitary requirements for the pasteurized milk. However, no standard is known to be established for the raw and UHT-treated milk.

\section{Quality and testing}

Good quality raw milk has to be free of debris and sediment; free of off-flavours and abnormal colour and odour; low in bacterial count; free of chemicals (e.g., antibiotics, detergents); and of normal composition and acidity. The quality of raw milk is the primary factor determining the quality of milk products. Good quality milk products can be produced only from good-quality raw milk.

The hygienic quality of milk is of crucial importance in producing milk and milk products that are safe and suitable for their intended uses. To achieve this quality, good hygiene practices should be applied throughout the dairy chain. Among the causes of small-scale dairy producers' difficulties in producing hygienic products is informal and unregulated marketing, handling and processing of dairy products; lack of financial incentives for quality improvement; and insufficient knowledge and skills in hygienic practices.

Milk testing and quality control should be carried out at all stages of the dairy chain. Milk can be tested for:

Quantity - measured in volume or weight;

Organoleptic characteristics - appearance, taste and smell;

Compositional characteristics - especially fat, solid and protein contents;

Physical and chemical characteristics;

Hygienic characteristics - hygienic conditions, cleanliness and quality;

Adulteration - with water, preservatives, added solids, etc;

Drug residues.

Examples of simple milk testing methods suitable for small-scale dairy producers and processors in developing countries include 
taste, smell, and visual observation (organoleptic tests); density meter or lactometer tests to measure the specific density of milk; clot-on-boiling testing to determine whether the milk is sour or abnormal; acidity testing to measure the lactic acid in milk; and the Gerber test to measure the amount of fat in the milk.

\section{Compositional quality of milk}

The composition of milk is not constant, but shows a wide variation. In the first place the composition depends on the species of animal. But also within a species we find big differences between the breeds and between individual animals within a breed. The composition might even change from day to day, depending on feeding and climate. But also during one milking the first milk differs from the last milk drops.

The species of dairy animal, its breed, age and diet, along with the stage of lactation, parity (number of parturitions), farming system, physical environment and season influence the colour, flavour and composition of milk and allow the production of a variety of milk products:

Cow milk contains approximately 3 to 4 percent fat of the solid content, protein about 3.5 percent and lactose 5 percent, but the gross chemical composition of cow milk varies depending on the breed.

For example, the fat content is usually higher in Bos indicus than B. taurus cattle. The fat content of milk from $B$. indicus cattle can be as much as 5.5 percent.

Buffalo milk has a very high fat content, which is on average twice as high as that of cow milk. The fat-to-protein ratio in buffalo milk is about 2:1. Compared with cattle milk, buffalo milk also has a higher casein-to- protein ratio. The high calcium content of casein facilitates cheese making.

Camel milk has a similar composition to cow milk but is slightly saltier. Camel milk can be three times as rich in vitamin $\mathrm{C}$ as cow milk and represents a vital source of this vitamin for people living in arid and semi-arid areas, who often cannot obtain vitamin $\mathrm{C}$ from fruits and vegetables. Camel milk is also rich in unsaturated fatty acids and B vitamins. Milk from Bactrian camels has a higher percentage of fat than milk from dromedaries, but levels of proteins and lactose are similar. Generally, camel milk is consumed raw or fermented.

Sheep milk has higher fat and protein contents than goat and cow milk; only buffalo and yak milk contain more fat. Sheep milk also generally has higher lactose content than milk from cows, buffaloes and goats. The high protein and overall solid contents of sheep milk make it particularly appropriate for cheese and yoghurt making. Milk from sheep is important in the Mediterranean region, where most of it is processed into cheeses such as pecorino, caciocavallo and feta.

Goat milk has a similar composition to cow milk. In Mediterranean countries and in Latin America, goat milk is generally transformed into cheese; in Africa and South Asia, it is usually consumed raw or acidified.

\section{Contamination of milk}

\section{Physical contaminants in milk}

Physical contaminants like dirt particles, hair, leaves, rubber and mettle particles, paper pieces etc. can get entry in to the milk at the time of milking. The dirt particles from air even, unclean udder or body of the cow, unclean utensils and water supply can contaminate milk. The hair of body of cow or of milk can also fall in the milk. The habits of 
the milker can also add some harmful contaminants like chewing tobacco, gutkha or beetle leaves can make entry of the physical contaminants into the milk.

At the barn, all the activities of the milker should be scrutinized. The cleaning of the milking equipment should be properly done with a reliable and adequate source of water supply. The dairy barns should be maintained regularly and of good condition. The surrounding area of the barn should be kept clean from the waste materials. The milking premises should be free from the cobwebs and accumulation of the dust particles.

\section{Chemical contaminants in milk}

Chemical Hazards are of concern in two respects first, environmental contaminants and second, adulterants added in milk which may cause illness or adverse health effects. There are several environmental contaminants that can affect the safety and quality of milk.

\section{Compositional quality of milk}

\begin{tabular}{|c|c|c|c|c|c|c|}
\hline Type of milk & Protein \% & Lactose \% & Fat \% & Total Solid \% & Ash \% & Moisture \% \\
\hline Human & 1.25 & 6.95 & 3.20 & 11.8 & 0.21 & 88.25 \\
\hline Goat & 3.30 & 4.40 & 3.90 & 12.0 & 0.70 & 88.0 \\
\hline Camel & 2.90 & 4.30 & 3.60 & 11.7 & 0.75 & 88.35 \\
\hline Cow & 3.40 & 4.80 & 3.75 & 12.8 & 0.71 & 87.23 \\
\hline Sheep & 6.35 & 5.0 & 6.90 & 19.3 & 0.85 & 80.70 \\
\hline Buffalo & 4.3 & 4.7 & 7.7 & 17.5 & .8 & 82.70 \\
\hline
\end{tabular}

(Source: Sabahelkhier et al., 2012)

Table.1 Maximum Residues Limits (MRLs) of some veterinary drugs in milk according to EU regulations

\begin{tabular}{|l|c|}
\hline \multicolumn{1}{|c|}{ Drugs } & Concentration $\left(\mathrm{\mu g} \mathrm{kg}^{-1}\right)$ \\
\hline Benzaylpenicillin & 4 \\
\hline Tetracyline & $100-200$ \\
\hline Oxytetracycline & 100 \\
\hline Chortracyline & 100 \\
\hline Trimethoprim & 50 \\
\hline Ceftiofur & 100 \\
\hline Streptomycin & $200-100$ \\
\hline Oxfendazole & 10 \\
\hline Sulphonamides & 100 \\
\hline
\end{tabular}

\section{Aflatoxins}

Aflatoxins and other mycotoxins are reported to be mutagenic, carcinogenic, tetratogenic and hepatotoxic in most animals and man. Aflatoxins present in the cattle feed are excreted in milk are known as M1, M2 and
M4, etc. Aflatoxin M1 (AFM1) may be found in the milk of animals that are fed with Aflatoxin B1 (AFB1) containing feed. The content of AFM1 in milk is entirely dependent on the presence of the precursor AFB1 in the ration of dairy cattle and it can numerically express as feed to milk ratio 
(Jahed Khaniki, 2007). These toxins can appear in milk within 48 hours of their intake through contaminated feed. It is important to have, regular monitoring for the presence of aflatoxins in milk. Heavy Metals for example lead; mercury, cadmium, arsenic, etc have been reported in milk. These contaminants are harmful / toxic if ingested in higher concentration than PFA norm.

\section{Pesticides and insecticides residue}

Pesticides are commonly used for control of insects on plants and animals. The common insecticides which may be present in milk are DDT, BHC (Benzene hexachloride), their isomers and other chlorinated compounds such as aldrin, dieldrin, heptachlor etc. The chlorinated hydrocarbons are extremely durable, persistent, endocrine-disrupting activities, bio-accumulating and widely distributed toxic compounds that find their way into the food chain usually through use in controlling environmental or animal pests (Mukerjee, 1998). As much as $20 \%$ of an ingested chlorinated hydrocarbon excretes in milk. Chlorinated hydrocarbons adhere to milk fat and butter contains a much higher proportion of these insecticides. DDT can accumulate in fatty tissues and can transfer into milk and dairy products. Organochlorine pesticides such as DDT and Hexachlorocyclohexane $(\mathrm{HCH})$ have banned in China since 1983. Residues of such compounds may persist in the environment and cause contamination through the food chain presented organochlorine pesticide residues (Owing to their use in sanitary actions) indicating a human exposure through milk and dairy products Wong and Lee, 1997). Radioactive Substances occur rarely in milk due to consumption of plants that are exposed to radiation produced by fission and fusion of nuclear material. Major radioactive substances are strontium 90 (90sr), Iodine 89(891) Barium140 (140Ba). Chemical fertilizers and growth promoters (Such as Hormones) have been used extensively to boost up agricultural production (USDA, 2002).

\section{Antimicrobial residue}

The most contentious residues that occur in milk are antimicrobial drugs. Much of the veterinary treatment of dairy cattle involves intra mammary infusion of antibiotics to control mastitis. Some drugs apply to control endoparasites, ectoparasites and several illnesses and to increase milk production (Korsrud et al., 1998.). The most commonly used antimicrobials in dairy cattle can group into five major classes. These include the beta-lactams (e.g., penicillins and cephalosporins), tetracyclines (e.g., Oxytetracycline, tetracycline and chlortetracycline), amino glycosides (e.g., streptomycine, neomycin and gentamycin), macrolides (e.g., erythromycin) and sulfanomides (e.g., sulfamethazines) (Mitchell et al., 1998.). Whenever any route with an antibiotic treats a lactating cow, measurable levels of the antibiotic are usually detectable in the milk for a few days after the last. There are Maximum Residues Limits (MRLs) for some drugs in milk according European Union (EU) regulations that have shown in Table 1 (European Commission, 1997).

\section{Antibiotic residue}

Although antibiotic residues in foods can have a detrimental effect on the processing of cultured products such as cheese and are important in terms of consumer confidence, the public health significance of residue concentrations of some of these compounds in foods from animals appears to be low, based on substantial scientific assessment. Most of the antibiotic drugs currently used in animal agriculture are relatively nontoxic, even at 
high concentrations, but there are a few antibiotics which pose a small but significant threat to public health when present in sufficiently high concentrations in foods. Among these is chloramphenicol, which has been associated (In a non-dose related manner) with a plastic anaemia due to bone marrow depression in a small proportion of human patients to whom the drug was administered for therapeutic purposes. Some of the patients who survive the bone marrow depression have developed leukemia, which creates concerns about possible carcinogenicity. Other antibiotics have been associated with allergic reactions of varying severity in people. An estimated four to ten allergic reactions occur per 100,000 courses of penicillin treatment administered directly to people, but actual incidents of allergic reaction to penicillin residues in foods are few and poorly documented. Although sulfonamides and tetracycline hydrochloride ministered to people at therapeutic concentrations may have toxic and allergic consequences. Based on experimental evidence, however, there is concern that residue concentrations of antibiotics have the potential to encourage the development of antibiotic resistance in the microbial flora of people eating contaminated foods (WaltnerToews and McEwen, 1994).

\section{Heavy metals residue}

Heavy Metals for example lead, mercury, cadmium, arsenic, etc. have been reported in milk. Heavy enter the human body mainly by the routes of inhalation and ingestion. With increasing environmental pollution, a heavy metal exposure assessment study is necessary heavy metals produce toxic effects by replacing essential metal ions existing in the chelates present in body. It is well established that lead $(\mathrm{Pb})$ and cadmium $(\mathrm{Cd})$ are toxic for human and children are more sensitive to these metals than adults. $\mathrm{Cu}$ and $\mathrm{Zn}$ are micronutrient and essential for living organisms, they can be toxic when taken in excess; both toxicity and necessity vary from element-to-element. Heavy metals can enter to milk and dairy products and affect the health of people who have consumed contaminate milk and dairy products (Raghunath, 1997).

\section{Hormone residue in milk}

\section{Steroid hormones}

Milk can also consider as a rich source of steroid hormones. The amounts of lipophilic hormones depend on the fat content of the milk and dairy products. Not only progesterone but also estrogen increases with fat content. Food processing does not seem to influence the amount and ratios of the hormones. In fresh cheese as well as in ripened cheese, testosterone was detected (0.1-0.5 $\left.\mathrm{mgkg}^{-1}\right)$. Probably not only propionic acid bacteria but also other fermenting bacteria or clotting enzymes are responsible for the formation of testosterone during the fermentation process (Hartmann, 1998).

\section{Bovine growth hormones}

Bovine Growth Hormone (BGH) or Bovine Somatotropin (BST) is a genetically engineered protein hormone either identical or similar to the natural bovine pituitary product. Its primary function is to increase milk production dairy lactating cattle. Therefore, BST is a protein hormone that increases milk production in cows between 10 and $15 \%$. An increase in milk yield typically occurs with 5 days after beginning of treatment. When BSTtreated cows were consuming sufficient quantities of nutrients to meet the energy needs for additional milk synthesis, body lipid mobilization did not increase, but lipid synthesis was instead reduced. BGH increases activity and/or longevity of mammary 
secretary cells, probably via Insulin-like Growth Factor (IGF)-I produced by the liver and/or the mammary gland. IGF-I is a portion of the effects of BST on lactation in dairy cow (Etherton and Bauman, 1998). The raw milk and pasteurized milk could have been levels of IGF-I of 5.6 and $8.2 \mathrm{ng} \mathrm{mL}^{-1}$, respectively. The infant formula could have been only trace amounts of IGF-I of $0.7 \mathrm{ng} \mathrm{mL} \mathrm{m}^{-1}$. Therefore, IGF-I is not destroyed by the pasteurization process but the heating of milk for the preparation of infant formula denaturizes IGF-I and significantly, reduction (35-48\%) levels of IGF-I compared to raw milk. BGH is probably stimulating immunological responses of animals and hence increasing the milk cell count. The US Food and Drug Administration (FDA) declared BGH officially "safe" in 1993, but it can cause to increase incidence of clinical mastitis in cows. This prompted concern that increased use of antibiotics to treat the mastitis might lead to increased residues of such drugs in milk. In news of the World Trade Organization has partially accepted European Union (EU) contentions for prohibiting the use of growthpromoting hormones in cattle (Layman, 1998).

Milk is considered a complete food because it contains proteins, fat, carbohydrates, minerals, vitamins and water. The quality of milk can be affected due to physical and chemical factors. Whereas milk produced under good handling practice from production, processing and up to consumption has good quality and its physicochemical composition. Physical contamination of milk can prevent with good practices but chemical contamination cannot completely prevent because it will find in fat or lipophilic contaminants. The use of food safety management and quality assurance in milk production and processing plant can much reduces the physiochemical contaminants in milk and milk products.

\section{References}

Etherton, T.D. and Bauman, D.E. 1998. Biology of somatotropin in growth and lactation of domestic animals, Physiol. Rev., 78(3): 745-61.

Europian Commission, 1997. Regulation laying down a community procedure for the establishment of maximum residue limits of veterinary medical products in foodstuffs of animal origin, Offic. J., 224: $1-8$.

Hartmann, S., Lacorn, M.and Steinhart, H. 1998. Natural occurrence of steroid hormones in food, Food Chem., 62: 720.

Haug, A., Hostmark, A.T., and Harstad, O.M. 2007. Bovine milk in human nutrition a review, Lipids in Health and Disease, $6: 25$.

Jahed Khaniki, G.R. 2007. Chemical Contaminants in Milk and Public Health Concerns: A Review, International Journal of Dairy Science, 2: 104-115.

Khan, M.T.G., Zinnah, M.A., Siddique, M.P., Rashid, M.H.A., Islam, M.A., and Choudhury, K. A. 2008. Physical and microbial qualities of raw milk collected from Bangladesh agricultural university dairy farm and the surrounding villages, Bangladesh Journal of Veterinary Medicine, 6(2): 217-221.

Kim, H., Hardy, J., Novak, G., Ramet, J.P., and Weber, F. 1983. Off-tastes in raw and reconstituted milk. FAO Animal Production and Health Paper, 35: 2

Korsrud, G.O., Boison, J.O. Nouws J.F.M., and MacNeil, J.D. 1998. Bacterial inhibition tests used to screen for antimicrobial veterinary drug residues in slaughtered animals, J. AOAC Int., 81: 21-24.

Layman, P. 1998. Murky who ruling on hormone- treated beef, Chem. Eng. News, 76: 12-12. 
Mitchell, J.M., Griffiths, M.W., McEwen, S.A., McNab, W.B., and Yee, A.E. 1998. Antimicrobial drug residues in milk and meat: Causes, concerns, prevalence, regulations, tests and test performance, A Review. J. Food Prot., 61: 742-756.

Mukerjee, D., 1998. Health risk of endocrine cause of injury and disease: a review. In Foodborne disrupting ortho substituted PCBs emitted from Disease Handbook, pp: 3. incinerators, Environ. Eng. Sci., 15: $157-169$

OECD 2005. Dairy policy reform and trade liberalization. Organisation for economic co-operation and development, p. 98, OECD Publishing.

Raghunath, R., Tripathi, R.M., Khandekar, R.N., and Nambi, K.S.V. 1997. Retention times of $\mathrm{Pb}, \mathrm{Cd}, \mathrm{Cu}$ and $\mathrm{Zn}$ in children's blood, Sci. Total Environ., 207: 133-139.

Sabahelkhier, M.K., Faten, M.M., and Omer, F.I. 2012. Comparative determination of biochemical constituents between animals (goat, sheep, cow and camel) milk with human milk, Res. J. Recent Sci., 1(5): 69-71.

Uddin, S. A. B. M. 1999. Effect of Refrigeration on the micropopulation of raw and pasteurized milk. M.S. Thesis, Department of Dairy Science, Bangladesh Agricultural University, Mymensingh.

United States Department of Agriculture (USDA), 2002. Judging and Scoring Milk and Cheese, Farmer's Bulletin No. 2259, United States Department of Agriculture, Washington DC.

Waltner-Toews, D., and McEwen, S.A. 1994. Chemical residues in foods of animal origin: overview and risk assessment, Prev. Vet. Med., 20: 161-178.

Wong, S.K., and Lee, W.O. 1997. Survey of organochlorine pesticide residues in milk in Hong Kong, J. AOAC Int., 80: 1332-1335.

\section{How to cite this article:}

Dilip Kumar, Dipti Rai, Paras Porwal and Sudhir Kumar. 2018. Compositional Quality of Milk and Its Contaminants on Physical and Chemical Concern: A Review. Int.J.Curr.Microbiol.App.Sci. 7(05): 1125-1132. doi: https://doi.org/10.20546/ijcmas.2018.705.137 